\title{
UM ESTUDO SOBRE A UTILIZAÇÃO DE MÉTODOS PEDAGÓGICOS NO DESENVOLVIMENTO DA APRENDIZAGEM DE ESTUDANTES AUTISTAS: UM ESTUDO DE CASO EM DUAS ESCOLAS PÚBLICAS DO MUNICÍPIO DE LUZ - MG
} A STUDY ABOUT THE USE OF PEDAGOGICAL METHODS IN THE DEVELOPMENT OF LEARNING OF AUTISTIC STUDENTS: A CASE STUDY IN TWO PUBLIC

SCHOOLS IN LUZ - MG

Mirele Melo Santos Correio. ${ }^{1}$

IFMG

Niltom Vieira Junior Correio ${ }^{2}$

IFMG

\begin{abstract}
RESUMO: No presente estudo foram abordadas teorias e métodos que podem ser utilizados pelos professores do ensino regular para aperfeiçoar o processo de ensino aprendizagem de alunos diagnosticados com Transtorno do Espectro Autista. O objetivo desta pesquisa foi verificar se professores de duas instituições de ensino regular da cidade de Luz - MG utilizam destes mecanismos e em caso afirmativo, quais resultados têm obtido através deles. Os dados foram obtidos através de entrevistas semiestruturadas realizadas com 14 profissionais que lidam com alunos autistas. Os resultados evidenciam que, apesar de ser um assunto bastante discutido atualmente, poucos são os métodos usados em sala de aula que contribuem para inclusão, atendem as necessidades e diminuem as limitações da aprendizagem dos alunos autistas. Os profissionais enfrentam obstáculos relacionados à falta de incentivo à capacitação, a escassez de materiais pedagógicos apropriados, entre outros. Verificou-se que ainda existem muitas dificuldades no processo de inclusão de alunos com Transtorno do Espectro Autista.
\end{abstract}

Palavras-chave: Autismo; Formação Continuada; Métodos de Ensino.

ABSTRACT: In the present study, theories and methods that can be used by regular teachers to improve the teaching and learning process of students diagnosed with Autistic Spectrum Disorder were discussed. The objective of this research was to verify if teachers of two regular education institutions in the city of Luz - MG use these mechanisms and if so, what results have been obtained through them. Data were obtained through semi-structured interviews conducted with two principals, X conducting teachers and two support teachers who deal with autistic students. The results show that, despite being a subject much discussed today, there are few methods used in the classroom that contribute to inclusion, meet the needs and reduce the learning limitations of autistic students. Professionals face obstacles related to lack of incentive for training, lack of appropriate teaching materials, among others. It was found that there are still many difficulties in the inclusion process of students with Autistic Spectrum Disorder.

Keywords: Pedagogical methods; Autism; Inclusion.

\footnotetext{
${ }^{1}$ Aluna do curso de pós-graduação em docência do IFMG.

2 Professor do curso de pós-graduação em docência do IFMG.

Cadernos Cajuína, v.5, n.3, Setembro-2020
} 


\section{INTRODUÇÃO}

A educação é um assunto amplo, que compreende diferentes tipos de aprendizagens, desde àquelas relacionadas aos valores, costumes e à personalidade cultural do cidadão individual e sua convivência em sociedade até a aprendizagem curricular, que trata da formação do indivíduo profissional, perante o mercado de trabalho.

Neste sentido, entende-se que a formação educacional começa dentro de casa, pela família, sendo que a mesma abrange em sua essência valores éticos e morais. O estado, através das escolas públicas, e a rede de ensino privada, oferecem ao cidadão a oportunidade do ensino científico, que o ajudará a se formar como cidadão e a adquirir conhecimentos acadêmicos.

Vale ressaltar que compreender as diferentes necessidades dos alunos é fundamental para que qualquer instituição de ensino possa desenvolver métodos pedagógicos adequados que possibilitem uma instrução de qualidade que atenda todos os alunos e especificamente àqueles que possuem algum tipo de necessidade especial.

A educação inclusiva defende que os alunos que possuem alguma necessidade especial possam ser acolhidos em instituições de ensino regular, recebendo o apoio necessário para que seja possível seu aprendizado.

No âmbito educacional, várias metodologias e estratégias pedagógicas são utilizadas com a finalidade de alcançar melhores resultados no processo de ensino-aprendizagem conforme estudos realizados por autores como, Orlanda e Santos (2013), Santos e De Fátima Rodrigues (2014), Barberini (2016). Na educação especial inclusiva, tais métodos pedagógicos buscam possibilitar que os alunos sejam inseridos no ensino regular, com condições de aprender e se desenvolver no mesmo patamar.

De maneira geral, os profissionais da área educacional precisam buscar alternativas, apoiando-se em teorias que tratam de diferentes maneiras de propiciar conhecimento aos alunos.

Diante do exposto, o objetivo do presente trabalho é analisar possibilidades metodológicas relacionadas ao ensino de alunos diagnosticados com autismo e verificar por meio de pesquisa em duas escolas públicas do município de Luz - MG, se professores utilizam destes mecanismos e em caso afirmativo, quais resultados têm obtido através deles.

No Brasil, estima-se de que 2 milhões de pessoas estejam no Espectro Autista (USP, 2015). Um avanço nas pesquisas para se alcançar dados precisos sobre o autismo se deve à Lei 13.861/19 (BRASIL, 2019). A Lei obriga o Instituto Brasileiro de Geografia e Estatística (IBGE) a inserir no 
Censo, a partir de 2020, perguntas relacionadas ao autismo. Desta forma, será possível saber quantas pessoas no Brasil apresentam esse transtorno e como elas estão distribuídas pelo território.

Segundo Silva (2011, p. 13):

O Autismo é um transtorno global do desenvolvimento que se caracteriza por dificuldades na interação social, dificuldades na comunicação e por padrões restritos e estereotipados de comportamentos. As pessoas com transtornos globais do desenvolvimento apresentam, em comum, alterações qualitativas das interações sociais recíprocas, na comunicação e comportamentos estereotipados e repetitivos, além de um estreitamento nos interesses e atividades.

Assim sendo, discutir e aprimorar a educação inclusiva tornou-se necessário, tendo em vista a importância da inserção de todos nos variados meios sociais. Além disso, este grupo social tem se conscientizado sobre seus direitos a acessos a benefícios públicos, especialmente no que tange a educação. A partir de então, estabeleceu-se a questão de pesquisa: os professores das escolas analisadas utilizam métodos pedagógicos apropriados no processo de ensino dos alunos portadores do Transtorno do Espectro Autista?

\section{EDUCAÇÃO NO BRASIL}

A educação é um forte viés de mudança pessoal, pois é através dela que o ser humano alcança sua dignidade e um futuro melhor para si. O desenvolvimento social da nação, a elevação da qualidade de vida, se faz importante quando refletimos e explicitamos o que sustenta tais pensamentos, no caso a educação. (ROTA JÚNIOR, 2014).

Tais bases teóricas são sustentadas em forma de lei, como por exemplo, o Art. $1^{\circ}$, Lei de Diretrizes e Bases da Educação Nacional - LDB (BRASIL, 1996), onde é mencionado que:

A educação abrange os processos formativos que se desenvolvem na vida familiar, na convivência humana, no trabalho, nas instituições de ensino e pesquisa, nos movimentos sociais e organizações da sociedade civil e nas manifestações culturais.

Vê-se ainda que o Art. 22 da LDB diz que “a educação básica tem por finalidades desenvolver o educando, assegurar-lhe a formação comum indispensável para o exercício da cidadania e fornece-lhe meios para progredir no trabalho e em estudos posteriores" (BRASIL, 1996).

Contudo, mesmo após todo o aparato legal existente, o Brasil ainda caminha lentamente neste quesito. Ao se destacar, por exemplo, a Educação Inclusiva vê-se ainda como uma demanda não totalmente compreendida, até mesmo por profissionais da área. 
A LDB assegura especificamente em seu Art. 58, que "entende-se por educação especial, para os efeitos desta Lei, a modalidade de educação escolar, oferecida preferencialmente na rede regular de ensino, para educandos portadores de necessidades especiais" (BRASIL, 1996).

Nota-se que este atendimento garantido por lei, deve proporcionar a integração de alunos com necessidades especiais e trazer um entendimento de que a escola abriria as portas para alunos com algum tipo de deficiência. Essa integração acontece quando os diversos tipos de aprendizagem são respeitados e utilizados como norteadores na realização de adaptações necessárias (BATISTA JR, 2008).

Dentro do mesmo conjunto, Kassar (2011, p.19), menciona que "a formação de uma educação especial brasileira deu-se dentro de um contexto de pouca atenção à educação pública em geral". Apesar dos recursos escassos e desafiadores, a educação nacional deve possibilitar a acessibilidade e a continuação de alunos com necessidades especiais na escola, completa (PAGLIARINI, 2016).

A inserção de alunos com necessidades especiais em escolas de ensino regular é um assunto que requer bastante atenção, pois são necessários alguns “ajustes” na estrutura, existe uma demanda por materiais e profissionais especializados que consigam atender tais alunos, de maneira eficiente e eficaz. Nessa ótica, faz-se a seguir uma breve descrição de algumas possibilidades metodológicas para tal atendimento.

\section{MODELO TEACCH}

Os alunos de uma mesma sala de aula apresentam diferentes tipos de aprendizagens e os professores que ali lecionam, precisam compreender tais peculiaridades e ensinar de maneira que todos consigam se desenvolver.

No caso de alunos diagnosticados com autismo, ainda há muito que ser compreendido e aperfeiçoado no contexto escolar. Tendo em vista que muitos profissionais não conhecem suas peculiaridades. Para Silva (2011, p. 20), “O autismo, tema complexo e instigante, ainda é desconhecido pela maioria dos profissionais da educação e até por alguns profissionais da saúde, o que impossibilita um atendimento adequado às pessoas que o possuem".

Dentre vários desafios da inclusão escolar da pessoa com TEA, está a dificuldade de fazêlas permanecerem na sala de aula e realizarem as atividades propostas pelo professor, por isso, compreende-se a necessidade do uso de recursos alternativos e métodos específicos para atender as diferentes formas do pensamento autista e das suas dificuldades cognitivas. (FERREIRA, 2016). 
Um tipo de procedimento de ensino diferenciado utilizado para promover a aprendizagem de autistas e pessoas com problemas relacionados à comunicação é o TEACCH (Treatment and Education of Autistic and Communication Related Handicapped Children).3 (FERREIRA, 2016).

Ferreira (2016, p.13) afirma ainda que:

O TEACCH é um modelo de intervenção que por meio de uma "estrutura externa", organização de espaços, materiais e atividades, permitem que a criança autista crie mentalmente "estruturas internas" que devem ser transformadas pela própria criança em estratégias e, mais tarde, automatizadas de modo a funcionar fora da sala de aula em ambientes menos estruturados.

O TEACCH não é um método composto por um conjunto de regras a serem seguidas. Assim sendo, o projeto trata-se de uma estruturação baseada em modelos de eixo visual com base na composição e na convenção de diversos recursos para aperfeiçoar a linguagem, aprendizagem de conceitos e mudança de comportamento (FERREIRA, 2016).

Vieira (2004, p.29) expõe que:

Antes de a criança ser inserida no programa TEACCH é feita uma avaliação funcional mediante a utilização de escalas de diagnóstico do autismo infantil, que possuem os seguintes objetivos: identificar crianças com autismo; classificar o nível de acometimento; e viabilizar o plano terapêutico.

A utilização de tal metodologia requer muito empenho de todos os profissionais envolvidos, considerando que para alcance de melhores resultados, serão necessárias adaptações envolvendo diversos aspectos relacionados à rotina, ao espaço físico, aos meios usados para auxílio na comunicação e interação dos alunos. É importante que tudo esteja organizado no sentido de proporcionar maior desenvolvimento e que os alunos possam vencer os obstáculos do autismo.

Em busca de promover a igualdade de oportunidade e uma educação de qualidade para todos, complementarmente a estes modelos pedagógicos, várias práticas foram criadas para auxiliar o professor regente a lidar com a inclusão em sala de aula. O estado do Paraná, por exemplo, criou em 2003, a função do professor de apoio, um professor que é responsável pelo acompanhamento do aluno com necessidade especial diariamente durante o horário escolar (SOUZA et. al., 2015).

Segundo Ambrós (2017, p.210):

Torna-se importante um trabalho em conjunto da professora da sala, com a educadora especial e também com outros profissionais para assim poder colocar em prática atividades convenientes que possam melhorar o desenvolvimento social, intelectual e afetivo do aluno com autismo.

\footnotetext{
${ }^{3}$ Tratamento e educação para autistas e crianças com déficits relacionados com a comunicação 
O trabalho de profissionais da educação especial vem se transformando em condição fundamental para educação e inclusão de estudantes com necessidades educacionais especiais (FREITAS, 2013).

Contudo, a efetividade da educação inclusiva nas escolas depende de diferentes aspectos, tais como, capacitação profissional, adequação do planejamento pedagógico e uma reorganização do ambiente.

\section{PESQUISA DE CAMPO}

O presente trabalho caracteriza-se como uma pesquisa descritiva exploratória, baseada em um estudo de caso, com abordagem qualitativa, onde se utilizou entrevistas semiestruturadas com questões abertas para responder aos objetivos.

Os sujeitos do estudo realizado foram os professores regentes de turmas e professores de apoio dos alunos portadores do Transtorno do Espectro do Autismo (TEA), de uma escola estadual e uma escola municipal localizadas em Luz - MG.

Os entrevistados responderam às questões livremente, que foram formuladas previamente através de um roteiro com questões abertas, conseguindo-se assim obter maior qualidade nas informações obtidas. Posteriormente as respostas foram analisadas e interpretadas para responder a questão da pesquisa ${ }^{4}$. Tais entrevistas foram realizadas com o objetivo de se obter informações sobre a maneira com que os profissionais trabalham a inclusão de alunos autistas em salas de aulas do ensino regular e a possível utilização de métodos pedagógicos específicos no processo de ensino aprendizagem dos alunos autistas das referidas escolas. Além disso, objetivou-se verificar se estes profissionais já conheciam e/ou já utilizaram o modelo TEACCH.

Os entrevistados foram selecionados por meio de uma amostragem não-probabilística, por conveniência, por serem os responsáveis pelo acompanhamento dos alunos autistas nas respectivas escolas analisadas. Toda a intervenção se deu no mês de setembro de 2019.

\footnotetext{
${ }^{4}$ Os instrumentos que guiaram as entrevistas podem ser vistos no Anexo I.
} 


\section{RESULTADOS E DISCUSSÃO}

$\mathrm{Na}$ Escola "A", foram realizadas entrevistas com 5 professores regentes, 1 professora de apoio e com a diretora. $\mathrm{Na}$ Escola "B", foram entrevistas 1 professora regente, 4 professores especializados (Empreendedorismo, Educação Religiosa, Educação Física e Arte), 1 professora de apoio e a diretora. Totalizando 14 profissionais.

Nas entrevistas com as diretoras das escolas foi identificado que há 1 estudante diagnosticado com Transtorno do Espectro Autista em cada uma das instituições, sendo um aluno do $2^{\circ}$ ano do ensino médio e o outro do $4^{\circ}$ ano do ensino fundamental. As diretoras e professores regentes afirmaram que é muito importante que esses alunos, assim como todos que possuem algum tipo de necessidade especial, sejam acompanhados e auxiliados por professor de apoio.

Ao serem perguntados sobre como ocorre a atuação dos professores regentes e professores de apoio no processo de ensino do aluno autista, os cinco professores regentes entrevistados da Escola " $A$ " relataram que são responsáveis por elaborar um planejamento semanal de aulas que é passado para a professora de apoio, que tem a função de adaptá-lo de acordo com as necessidades e limitações do aluno autista. Segundo eles, muitas vezes a professora de apoio recorre à internet para obter materiais que facilitem a aprendizagem do aluno. Uma das professoras ressaltou que procura envolver o aluno autista nas atividades e para isso, formula perguntas de maneira mais “simples" para que ele participe da aula e consiga absorver melhor o conteúdo.

$\mathrm{Na}$ Escola "B" as professores destacaram que tentam levar atividades lúdicas que possibilitem maior envolvimento do aluno autista e muitas vezes ele consegue interagir com os demais alunos.

Quando perguntado sobre quais são as maiores dificuldades encontradas pelos profissionais para trabalharem com alunos autistas, as diretoras os professores destacaram a falta de materiais pedagógicos adequados e suficientes, que auxiliem a compreensão do aluno e saber lidar com a própria dificuldade de socialização do autista, que é uma forte característica do transtorno. Os professores de apoio das duas escolas enfatizaram que além de ser difícil a socialização, o aluno autista também possui limitações em obter autonomia e o processo de ensino dos conteúdos é complexo.

Os entrevistados foram perguntados se já participaram de algum curso de capacitação em educação especial. Dentre todos os professores regentes e de aulas especializadas entrevistados, somente 2 pessoas na Escola "A" afirmaram já ter participado de programas de formação continuada nessa área. As professoras de apoio, que são formadas em educação especial, relataram que buscam e participam de cursos voltados para esta área, no entanto, destacaram que o sistema 
de ensino e o Estado, não oferecem complementação curricular satisfatória e que os mesmos, quando se interessam, devem buscar sozinhos por isso. As diretoras também responderam que não há esse tipo de incentivo por parte do governo.

Quanto às opiniões dos profissionais entrevistados sobre quais seriam os principais benefícios de cursos voltados para capacitação dos professores para atendimento ao autismo, suas respostas destacaram o fato de poderem obter maior compreensão sobre como se dá o processo de aprendizagem, quais são as limitações destes alunos e quais os melhores métodos ou modelos disponíveis para esse atendimento.

Foi perguntado a todos os profissionais entrevistados se os mesmos conhecem e/ou utilizam o modelo TEACCH ou alguma outra técnica ou metodologia específica utilizada no processo de ensino de autistas. Dentre os professores, apenas uma professora regente e as 2 professoras de apoio, afirmaram conhecê-lo, porém somente estas últimas relataram já ter utilizado tal recurso e conhecerem outros.

Os profissionais destacaram que não trabalham com métodos específicos e que muitas vezes recorrem a pequenas e às vezes improvisadas estratégias, pois, de acordo com as condições oferecidas na escola, o processo de ensino do aluno autista se torna ainda mais complexo.

Os resultados obtidos nesta investigação mostraram que ainda há muito por avançar na educação especial e na inclusão de autistas no ensino regular, pois a prática deste processo ainda enfrenta grandes desafios e diversas limitações.

\section{CONSIDERAÇÕES FINAIS}

Constatou-se no trabalho que a educação inclusiva e especial, apesar de ganhar espaço na literatura, ainda não ocorre de maneira concreta em todas as instituições escolares, haja vista as realidades vivenciadas nas escolas investigadas.

Observou-se que os aspectos estruturais e didáticos ainda precisam ser melhorados. Contudo, salientam-se os aspectos conceituais, visto que há diversas dificuldades que problematizam, ainda mais, as abordagens dos professores nas salas de aula. Embora, seja evidente que os profissionais busquem estratégias para o ensino inclusivo, ainda lhes faltam conhecimento científico advindo, além da experiência, de programas e estímulo à formação continuada.

Prova disto é que os professores das duas escolas analisadas não utilizam métodos pedagógicos específicos trazidos por autores, como o TEACCH para ensinar os alunos autistas, pois ainda se vêem diante de muitas limitações que impossibilitam a utilização deste e/ou outros recursos. 
Como destaque afirma-se que, embora ainda insipiente, os resultados já tendem a se mostrar mais produtivos quando o conjunto de profissionais envolvidos (por exemplo, professor regente e de apoio) trabalham em sintonia.

\section{REFERÊNCIAS BIBLIOGRÁFICAS}

AMBRÓS, D. M.. O aluno com Transtorno do Espectro Autista na Sala de Aula: caracterização, legislação e inclusão. In: $1^{\circ}$ SEMINÁRIO LUSO-BRASILEIRO DE EDUCAÇÃO INCLUSIVA: O ENSINO E A APRENDIZAGEM EM DISCUSSÃO, 1., 2017, Santa Maria. Anais... . Santa Maria: Pucrs, 2017.v. 1, p. 209-220.

BARBERINI, K. Y.. A escolarização do autista no ensino regular e as práticas pedagógicas. Cadernos de Pós-Graduação em Distúrbios do Desenvolvimento, v. 16, n. 1, 2016. Disponível em: <http://editorarevistas.mackenzie.br/index.php/cpgdd/article/view/11291>. Acesso em: 06 de mai. 2019.

BATISTA JÚNIOR, J. R. L.. Pesquisas em Educação Inclusiva: Questões Teóricas e Metodológicas. Pipa Comunicação. Recife, 2016. Disponível em: < http://www.ufpb.br/cia/contents/manuais/livro-pesquisas-em-educacao-inclusiva.pdf $>$. Acesso em: 01 mai.2019.

BRASIL. Presidência da República. Casa Civil. Lei de Diretrizes e Bases da Educação Nacional, LDB $\mathrm{n}^{\circ}$ 9394, de 20 de dezembro de 1996. Disponível em: <http://www.planalto.gov.br/ccivil_03/Leis/L9394.htm>. Acesso em: 19 de abr. 2019.

BRASIL. Presidência da República. Casa Civil. Lei de Especificidades Inerentes ao Transtorno do Espectro Autista, n¹3. 861 de 18 de julho de 2019. Disponível em: < http://www.planalto.gov.br/ccivil_03/_ato2019-2022/2019/lei/L13861.htm>. Acesso em: 18 ago.2019.

FERREIRA, P. P. T.. A inclusão da estrutura TEACCH na educação básica. Frutal: MG, Ed. Prospectiva, 2016. Disponível em: <https://www.aacademica.org/editora.prospectiva.oficial/24.pdf $>$. Acesso em: 29 de jun. de 2019.

FREITAS, A. de Oliveira. Atuação do professor de Apoio à Inclusão e os Indicadores de Ensino Colaborativo em Goiás. 2013. 123 f. Dissertação (Mestrado em Educação) Universidade Federal de Goiás, Catalão, 2013. Disponível em:< http://repositorio.bc.ufg.br/tede/handle/tede/3105>. Acesso em: 24 jul. 2019.

KASSAR, M. de C. M.. Educação Especial na Perspectiva da Educação Inclusiva: Desafios da Implantação de uma Política Nacional. Educar em revista, Curitiba, Brasil, n.41, p. 61-79, jul./set.2011. Ed. UFPR. Disponível em: < http://www.scielo.br/pdf/er/n41/05.pdf>. Acesso em: 01 mai.2019.

OLIVEIRA, C. Espaço Aberto. Comportamento, São Paulo, Coordenadoria de Comunicação Social - CCS/USP, n. 170, p. on-line, 2015. Disponível em: < 
http://www.usp.br/espacoaberto/?materia=um-retrato-do-autismo-no-brasil >. Acesso em: 26 jul.2019.

ORLANDA, T. M. T.; SANTOS, J. C. dos. Metodologias Utilizadas pelos Professores do Ensino Regular para Promover a Aprendizagem dos Alunos com Deficiência. Nativa-Revista de Ciências Sociais do Norte de Mato Grosso, v. 1, n. 2, 2013. Disponível em:< https://docplayer.com.br/14495825-Metodologias-utilizadas-pelos-professores-do-ensinoregular-para-promover-a-aprendizagem-dos-alunos-com-deficiencia.html>. Acesso em: 20 jul.2019.

PAGLIARINI, C. D.. Educação inclusiva na educação básica: revisão bibliográfica no Brasil. Trabalho de conclusão de curso (bacharelado - Ciências Biológicas) - Universidade Estadual Paulista Julio de Mesquita Filho, Faculdade de Engenharia de Ilha Solteira, 2016. Disponível em: <http://hdl.handle.net/11449/149290>. Acesso em: 19 de abr. 2019.

ROTA JÚNIOR, C.. Educação e Mobilidade Social: Um Estudo sobre a Legislação Educacional Brasileira. Educ. Soc.Cult. 2013, 169-184. Faculdades Integradas Pitágoras de Montes Claros (FIPMOC) e Universidade Federal de Minas Gerais (UFMG) (Brasil). Disponível em: < https://www.fpce.up.pt/ciie/sites/default/files/11.CesarRotaJunior.pdf >. Acesso em: 19 de abr. 2019.

SANTOS, A. M.; DE FÁTIMA RODRIGUES, M. do R.. Métodos e procedimentos utilizados na educação especial na perspectiva da educação inclusiva. Veras, v. 4, n. 1, p. 37-61, 2014. Disponível em:

http://site.veracruz.edu.br/instituto/revistaveras/index.php/revistaveras/article/view/158>.

Acesso em: 30 abr. 2019.

SILVA, E. C. S.. A prática pedagógica na inclusão educacional de alunos com autismo. Salvador, 2011, 166p. Dissertação (Mestrado) - Universidade Federal da Bahia. Disponível em: < http://repositorio.ufba.br/ri/handle/ri/9684>. Acesso em: 20 de jun. 2019.

SOUZA, F. F.; VALENTE, P. M.; PANNUTI, M. O papel do professor de apoio na inclusão escolar. In: CONGRESSO NACIONAL DE EDUCAÇÃO, 12., Curitiba, 2015. Anais... Curitiba: PUCPR, 2015.

VIEIRA, S. A.. O Tratamento e Educação para Autistas e Crianças com Déficit Relacionado à Comunicação - TEACCH: um estudo de uma proposta pedagógica em uma Escola Especial da Cidade de Colombo - PR. Universidade de Tuiti do Paraná. Curitiba, 2004. Disponível em:< https://tcconline.utp.br/wp-content/uploads//2013/06/O-TRATAMENTO-E-EDUCACAOPARA-AUTISTAS-.pdf>. Acesso em: 01 de set. 2019. 


\section{ANEXO 1- INSTRUMENTOS BASE PARA ENTREVISTA}

\section{Roteiro de entrevista - Diretoria}

1- Há algum aluno portador de Transtorno do Espectro do Autismo (TEA)? Caso afirmativo, qual ano está cursando?

2- Em sua opinião, quais os benefícios decorrentes de cursos voltados para capacitação dos professores da escola para lecionarem para alunos especiais? E especificamente para alunos portadores de autismo?

3- O sistema de ensino oferece aos professores algum tipo de complementação curricular para que os mesmos possam trabalhar adequadamente com alunos diagnosticados com autismo?

4- Na escola há algum professor de apoio aos alunos com necessidades especiais? Qual sua formação e como se dá sua atuação em sala de aula?

5- O estado/município oferece métodos e/ou materiais pedagógicos adequados e suficientes para facilitar o processo de ensino dos alunos portadores de autismo?

6- Quais as maiores dificuldades encontradas pela equipe escolar no dia-a-dia para trabalharem com alunos autistas? O que é feito para tentar superá-las?

7- Que tipo de ação pode ser sugerida, no sentido de tornar eficaz a inclusão do aluno com autismo na escola regular?

8- Como a escola interage com os familiares dos alunos autistas? As famílias são presentes e acompanham a vida escolar dos mesmos?

\section{Roteiro de entrevista - Professores regentes}

1- Qual disciplina você leciona? 
2- Como ocorre sua atuação em relação ao(s) alunos autistas, juntamente com o profissional da educação especial (professor de apoio)?

3- Quais as maiores dificuldades encontradas por você para trabalhar com alunos autistas?

4- Em sua opinião, quais os benefícios decorrentes de cursos voltados para capacitação dos professores da escola para lecionarem para alunos especiais? E especificamente para alunos portadores de autismo?

5- Você já participou de algum curso de capacitação em educação especial?

6- O sistema de ensino oferece aos professores algum tipo de complementação curricular para que os mesmos possam trabalhar adequadamente com alunos diagnosticados com autismo?

7- O estado/município oferece métodos e/ou materiais pedagógicos adequados e suficientes para facilitar o processo de ensino dos alunos portadores de autismo?

8- Você conhece o TEACCH (Tratamento e educação para autistas e crianças com déficits relacionados com a comunicação), um tipo de procedimento de ensino diferenciado utilizado para promover a aprendizagem de autistas e pessoas com problemas relacionados à comunicação? Já utilizou este método ou outro?

9- Que tipo de ação pode ser sugerida, no sentido de tornar eficaz a inclusão do aluno com autismo na escola regular?

10- Em sua opinião, é necessário haver um professor de apoio para auxiliar os alunos portadores de necessidades especiais nas atividades?

11- Como se dá a atuação do professor de apoio em sala de aula?

12- A presença de alunos autistas dificulta o processo de aprendizagem dos demais alunos?

Roteiro de entrevista - Professores de apoio 
1- Como ocorre sua atuação como profissional da educação especial juntamente com os professores regentes de cada disciplina?

2- Como você ensina o aluno autista? Você faz o planejamento de atividades para este aluno?

3- Você utiliza algum método pedagógico diferenciado? Fale um pouco sobre isso.

4- Como o aluno se comporta no momento de realização das atividades propostas a ele?

5- Em sua opinião a maneira como você ensina os conteúdos ao aluno autista é eficiente? Ele demonstra bons resultados de aprendizagem?

6- Você conhece o TEACCH (Tratamento e educação para autistas e crianças com déficits relacionados com a comunicação), um tipo de procedimento de ensino diferenciado utilizado para promover a aprendizagem de autistas e pessoas com problemas relacionados à comunicação? Já utilizou este método ou outro?

7- Quais as maiores dificuldades encontradas por você para se trabalhar com alunos autistas? O que você faz para tentar superá-las?

8- Como a escola interage com os familiares dos alunos autistas? As famílias são presentes e acompanham a vida escolar dos mesmos?

9- Qual ou quais as suas sugestões para que o processo de inclusão seja melhorado e se torne mais efetivo na rede pública de ensino?

10- A presença de alunos autistas dificulta o processo de aprendizagem dos demais alunos? 